\title{
Predicament and Development Strategy of Traditional Wushu's External Communication
}

\author{
Zhu Hainan, Wang Linan \\ Xi'an Physical Education University, Xi'an, Shaanxi 710000
}

Keywords: Traditional Wushu; external communication; predicament; development strategy.

\begin{abstract}
Traditional Wushu culture has an irreplaceable role in the culture of our country. It is necessary to push traditional Wushu into the world, let more people realize the traditional martial arts, and sincerely love it, so it is essential to better complete the traditional Wushu exchange. However, in this process, because of many reasons, there are difficulties in the whole process. This paper will study what difficulties traditional Wushu meets in foreign exchange and give relevant solutions according to the causes of these difficulties.
\end{abstract}

\section{Introduction}

Traditional Wushu, as a long-term and continuous social practice of the Chinese nation and the cultural gem created by the accumulation, represents the essence of Chinese culture and is our pride. Traditional Wushu originated in China, but it is the world. Therefore, it is the essence of Chinese traditional culture and the cultural wealth of the people all over the world. How to carry forward the best Chinese traditional culture is the responsibility given to us in this era. The traditional Wushu culture can communicate with other cultures. The integration of the traditional Wushu can inspire the wisdom of the people, and can inject new life into the traditional Wushu culture, and bring a wider space for development. Therefore, we should actively introduce and publicize to the world. It enables everyone to recognize traditional Wushu and recognize traditional martial arts. Only in this way can traditional Wushu be brought to the international arena. Traditional Wushu's foreign exchange itself is in cross culture, and needs to cross national boundaries. Under this premise, the traditional Wushu exchange is not only a relatively fixed race, social group, and the country is a relatively single value system and ideology. According to the relevant data, the differences between cultures will bring considerable constraints to cross-cultural communication. The greater the difference between cultures, the difficulty and obstacles to the cultural exchanges between foreign countries and the obstacles will increase. So. In order to enable the excellent culture of traditional martial arts to play a more important role in the world, more and more people can understand this culture more deeply, we must solve the difficulties that traditional Wushu will encounter in the exchange of foreign Wushu, and carry on deep research and give relevant solutions.

\section{Difficulties and Causes for Traditional Wushu's External Communication}

The communication of traditional Wushu is usually based on the traditional Wushu culture, which is propagandize and carry forward the traditional Wushu culture through individual, team, government department and scientific means. This article is mainly from the orientation of traditional Wushu culture, the ability to understand the audience, the manner of external communication, and mysticology. In order to find out the difficulties and reasons for external communication, we will conduct in-depth analysis of international market and other reasons[1].

Chinese Traditional Wushu has been accumulated and precipitated by a long period of culture, which combines various traditional cultures such as philosophy, religion, art and folk customs. Therefore, traditional martial arts are not only pure fighting skills and fitness methods, which represent a long and profound history of traditional Wushu, so it is also attracted to the traditional Wushu. A part of the foreign audience's love and learning. However, with the invasion of imperialist powers in modern times, the entire Chinese nation suffered unimaginable disasters. The once - 
inspiring Chinese martial arts had no way to save China at that time. At the same time, Chinese Wushu was basically not passed out. Under the influence of this environment, the development of Chinese traditional martial arts was seriously hindered and failed to get out of the country. After the founding of new China, traditional Wushu has been difficult to find its own position in international competitions. After decades of development, in some of the current international fighting competitions, although the shadow of Chinese martial arts can be seen, the overall performance still can not achieve the desired effect. Most of the people will forget in this situation. The reason for this situation and the unique connotation of traditional culture are to negate traditional martial arts only from the aspect of fighting. It is thought that traditional Wushu is only a flower shelf, and it does not possess gold content. There is a law of cultural communication, which is like flowing water. The culture of high potential energy will be exported to the low potential energy culture, and the traditional Wushu in China is at the low potential at present, which makes the traditional Wushu be in a passive state when communicating with the outside world. In this case, the traditional Wushu must find a reasonable position to carry out the active communication, strengthen the intensity of foreign exchange, and carry forward the traditional Wushu with Chinese characteristics to all countries in the world.

The communication of traditional Wushu culture itself is to communicate and collide with each other through different cultures, and it belongs to intercultural communication. However, the most difficult part of this kind of communication is whether the receiving crowd can understand. For those who have never known the traditional Wushu culture, the first problem that needs to face is the characteristics of the traditional Wushu itself, namely, the virtuality, the procedural style and the unique aesthetic, and the traditional martial arts are different from the style of free fight. The traditional martial arts boxing of each door has a fixed standard action to express, and this expression is conventional, familiar people can understand quickly, but it is certain that it is difficult for other countries to accept it. Therefore, only relying on the practice of martial arts, the foreign audience can not understand the mystery of traditional martial arts, and can not truly recognize the cultural connotation of traditional Wushu. From another perspective, the difficulty of audience understanding comes from the translation of professional languages. To some extent, the movements of Wushu can be communicated across languages, but the audience wants to understand the mysteries of them. They still need a language to answer them. They want to understand the meaning expressed by the martial arts, and the language can be better explained. Therefore, it is very important for the translation of the language to be accurate, to translate the characteristics of the martial arts, the course of action and the meaning of the attack and defense. It can not be translated directly. It is also difficult to take away the original intention of Wushu and to consider whether the foreign audience understands it, and it is very difficult to keep the original flavor of the traditional Chinese martial arts. In this regard, the talent is scarce, many translators themselves do not understand the professional knowledge of Wushu, not to mention deep understanding of the connotation of Wushu, which leads to the existence of a certain gap between the content and the reality of the translation, and it is difficult to elaborate the cultural connotation of the traditional Wushu. Therefore, the relevant translation staff of traditional martial arts must have solid language skills, excellent translation skills and understanding of Chinese traditional martial arts. And how to improve the comprehensive ability of the traditional Wushu translators is a major problem in the current foreign exchange[3].

In order to be able to enter the games, Wushu is divided into three aspects: Competitive Wushu, Sanda and traditional Wushu. Competitive Wushu is the first choice for Wushu to enter the Olympic Games. In order to meet the standards of international referee, competitive Wushu refers to the development form and scoring standard of competitive gymnastics to make competitive Wushu lack the traditional cultural charm. The chairman of the Olympic Games, Mr. Marangi once said, "competitive Wushu is a martial art, but it is more like a Chinese style floor exercise." This ironic evaluation makes Wushu's entry into the Olympic Games a distant dream. At present, competitive Wushu, as the main item to enter the Olympic Games, is still in the leading position in China. And Sanda is the use of westernized training mode, with boxing, Thai boxing, western style of fighting 
the same mode, mainly in the domestic competition, Sanda is indeed to a certain extent to achieve the unique charm of Chinese Kungfu, but if not to do antagonistic training, then the traditional Wushu is still a few people. If the popularization of traditional Wushu has been "catered for", it will always be in a passive position, and it will be difficult to develop for a long time. The propaganda and promotion of Chinese Traditional Wushu must improve people's deep excavation and management of the cultural connotation of traditional Wushu. It is the only way to increase the content of the traditional Wushu, to serve the new vitality of the traditional martial arts, and to guide the foreign people to the virtues and the unity of heaven and man. To improve the awareness of the traditional Chinese martial arts, to improve the awareness of traditional Wushu, and to ensure that the enthusiasm for learning wushu is more lasting, which will inevitably bring more positive influence on the propaganda of traditional Wushu[4].

Chinese Traditional Wushu is the crystallization of the National People's wisdom and represents the traditional Chinese culture. Traditional Wushu is the behavior of people in life in order to better protect themselves from injury. It represents the wisdom of the people of the whole country, but the path of its development has been influenced by historical limitations. There are many shortcomings of the wisdom left by the ancient people in traditional martial arts, which are not much because of the mystical mystery of mythology, superstition and martial arts, and this mystique. It causes people to misunderstand the martial arts and obscured the essence of the traditional Wushu culture. For example, the mysterious Chinese Kungfu, such as "the mountain beat cattle" and other mysterious Chinese Kungfu, people are very difficult to understand the traditional Wushu, which affects the development of traditional Wushu in this society. If we want to better spread Chinese Wushu culture, we must uncover this mystery and make traditional Wushu more popular.

With the increasing efforts of the country to promote Wushu, the opportunity for traditional Wushu to go out of the country is also increasing. However, most of these activities are arranged by relevant government departments. Most of the spectators are foreign friends and a few martial arts professionals attended by courtesy, mainly by overseas Chinese and students. The performance of Chinese traditional martial arts abroad is more emphasis on communication rather than marketization, and no operation mechanism with international influence has been formed. Although the purpose of the cultural exchange of traditional Wushu is not reflected by the market share, the audience is only among the Chinese people, so the exchange of traditional Wushu becomes cultural "Consolation". From the meaning level of intercultural communication, Chinese Traditional Wushu is the representative and embodiment of the traditional culture of the Chinese nation. People from other ethnic groups and other cultures can better understand Chinese culture by understanding and understanding Chinese traditional martial arts. If the audience of the overseas Wushu performance is too concentrated in Chinese people, it will be difficult for the international audience to understand and understand the Chinese culture through Wushu. Most of the foreigners who travel to China experience traditional Chinese culture through watching martial arts. This performance, which relies on the tourism market, has great liquidity and uncertainty, and the possibility of becoming a loyal fan of traditional martial arts is not very likely. Therefore, without the establishment of a stable international sports market, the foreign exchange of Chinese Traditional Wushu is difficult to carry out deeply. It is difficult to realize the task of introducing Chinese Traditional Wushu culture to the world[5].

\section{Development Strategies for the External Communication of Traditional Wushu}

The popularization of traditional Wushu is a long-term and complex system project. We must have a high professional team to improve the efficiency and influence of foreign exchange activities, and enhance the breadth and depth of foreign exchange. This is a high demand for local disseminators and promoters. They should not only have exquisite skills, but also have high cultural attainments, and have a clear understanding of the cultural level of traditional martial arts. Therefore, when we train traditional Wushu to promote professional skills, we should vigorously improve their traditional martial arts literacy. It is suggested that traditional Wushu, as the main sport course, enter the classroom of large, middle and primary schools, improve the traditional 
Chinese Wushu population, make more people understand the traditional Wushu culture more clearly, and make a good foundation for our country to train business personnel to exchange business with foreign business in an all-round way. Only when our own business people really grasp the technical and cultural connotations of traditional Wushu can we transmit the information of traditional Wushu more accurately to the audience. Therefore, improving people's traditional Wushu culture and training professional promotion talents is an important strategy to realize our traditional Wushu's external communication.

In the long river of the history and culture of the nation, traditional Wushu has rich cultural ideas and details. Before, the inheritance and development of traditional Chinese martial arts mainly depend on the "help" of the old Wushu family. This kind of inheritance can not be adapted to the development of the present society. Therefore, the relevant government departments pay more attention to the strengthening of the traditional Wushu. The promotion process and construction of traditional Wushu culture, making the plan of digging, sorting, protecting and inheriting, strengthening the propaganda of Chinese Traditional Wushu culture, strengthening the promotion of the whole world, establishing the standardization of the Chinese Traditional Wushu culture system, and then actively and correctly expressing itself to the world[6].

In the exchange of traditional Wushu, we should strengthen the culture and education of the disseminators, innovate the ideas, improve the means of popularization, change the "catering" to "guide", use modern means and methods of communication, expand the channels of communication, and use the popular language, text and network media to disseminate Chinese Wushu. We should also establish and improve the traditional Wushu competition system, establish a platform for competition and network communication, and then regularly hold some traditional Wushu competitions at home and abroad, which will not only make the foreign audience accept the edification of Chinese Traditional Wushu culture, but also protect the spiritual lifeblood of Chinese Traditional Wushu, at the same time We should carry out in-depth exchanges and development of traditional Wushu.

Relevant data show that cultural differences restrict the spread of cross-cultural communication. The greater the cultural difference, the greater the barrier to external communication. There is an objective existence of the differences between Chinese and Western culture in the foreign exchange of traditional Wushu in our country. It is a long process of psychological conquest that Chinese Traditional Wushu should be recognized by foreign audiences, and it needs to be guided correctly. Max Webb, a famous sociologist, believes that any social action needs the support of invisible social spirit. Therefore, in the traditional Wushu exchange, we should face the difference between Chinese and Western culture. Through the development of the traditional Wushu, the professional people who know the essence of the traditional Wushu culture are the important basis and premise of the Chinese Traditional Wushu culture coming out of the country and spreading to the world face to face.

\section{References}

[1] Chen W, Fan Q, Zhang Y. A Study on the Dilemma and Development Countermeasures of Wushu Course in Universities from the Aspect of Wushu's Essence [J]. Chinese Wushu Research, 2017.

[2] Gu B, Wang Y, Qi W. Dilemmas and Solutions:the Influence of Sinology Education on Chinese Wushu[J]. Chinese Wushu Research, 2017.

[3] Song B, Ding B, Of S. The Development Strategy for Wushu Competition in BeijingTianjin-Hebei Area—Taking Beijing-Tianjin-Hebei Traditional Wushu Exchange Contest as an Example[J]. Chinese Wushu Research, 2017.

[4] Yuan S, Qian P. The Dilemma,Development and Shift of the US Central Asia Strategy[J]. Frontiers, 2016.

[5] Wang L, Lun H, Yin H. A Research on the Development Strategy of the Industrialization of 
Traditional Wushu under the Background of "Sports +”[J]. Chinese Wushu Research, 2017.

[6] Liu F H, Yang B S, Zhang H, et al. Development Strategy of National Traditional Sports Cultural Industry Based on SWOT-AHP Model[J]. Journal of Beijing Sport University, 2016 